\title{
SENTENCIAS JUDICIALES Y EFECTIVIDAD DE DERECHOS CONSTITUCIONALES: UN ANÁLISIS DESDE LAS CATEGORÍAS DE CULTURA POLÍTICA Y JURÍDICA
}

\author{
JUDGMENTS AND EFFECTIVE PROTECTION OF THE \\ CONSTITUTIONAL RIGHTS: AN ANALYSIS BY CATEGORY \\ OF POLITICAL AND LEGAL CULTURE
}

Luis Esteban Caro Zottola*

SUMÁRIO: Introducción. 1 Desarrollo. 1.1 El moderno concepto de cultura política. 1.2 La cultura política y su vinculación con la cultura jurídica. 1.3 El estudio las diferentes culturas jurídicas en el caso argentino. Consideraciones finales. Bibliografía.

RESUMEN: El contraste entre el reconocimiento formal de los derechos y su efectivo cumplimiento ha reavivado el debate de los problemas de acceso a la justicia, especialmente vinculados con las sentencias judiciales como última etapa destinada a la salvaguarda de los derechos. En Argentina, luego de la Reforma Constitucional de 1994, se ha podido observar un conjunto de decisiones judiciales que muestran una gran variedad de criterios, incluso antagónicos, a la hora de resolver la protección de los derechos constitucionales, lo que ha motivado fijar la atención en las prácticas llevadas a cabo por los órganos jurisdiccionales. En este marco, este trabajo propone una línea de explicación de las diferentes posiciones que pueden realizar los jueces en las sentencias, utilizando las nociones de cultura política y cultura jurídica, categorías analíticas que pueden permitir explicaciones más profundas acerca de los problemas en la garantía de los derechos. Para este fin se realiza un breve planteo de la problemática, para luego analizar la noción de cultura política y su vinculación con la de cultura jurídica y examinar, a modo de ejemplo, la utilización de la propuesta en el caso argentino. Finalmente se exponen las conclusiones provisorias del trabajo.

Palabras claves: Cultura Política. Cultura Jurídica. Poder Judicial. Derecho Constitucional.

\begin{abstract}
The contrast between the formal recognition of rights and his effective protection has revived the debate on the problems of access to justice, particularly related to judicial decisions. In Argentina, after the constitutional reform of 1994, it has been observed a number of judgments that show a variety of criteria, even antagonistic, to solving the protection of constitutional rights, which has led to focus attention practices carried out by the courts. In this context, this paper proposes a line of explanation of the different positions that can make judges, using the notions of political culture and legal culture, analytical categories that may enable deeper explanations
\end{abstract}

\footnotetext{
* Consejo Nacional de Investigaciones Científicas y Técnicas (CONICET). Universidad Nacional de Tucumán (UNT).
} 
about the problems in the effective protection to human rights. To this purpose, a brief posing of the problem, and then analyze the notion of political culture and its relationship to the legal culture and examine, as example, the use of the proposal in the Argentine case. Finally we present the conclusions.

Keywords: Political Culture. Legal Culture. Judiciary. Constituicional Right.

\section{INTRODUCCIÓN}

En Argentina, los avances normativos logrados con la Reforma Constitucional de 1994 a partir de la incorporación de un completo sistema de derechos humanos, no se han visto necesariamente acompañados por una mayor protección efectiva de ellos, especialmente en los sectores más vulnerables de la sociedad.

Esta separación entre el derecho formalmente reconocido y su efectivo cumplimiento, ha reeditado las discusiones acerca de los problemas de acceso a la justicia y del papel del Poder Judicial en la garantía de los derechos.

La atención puesta en las decisiones de los jueces se revitaliza cuando se puede observar en la práctica jurisdiccional una amplia heterogeneidad de decisiones, incluso antagónicas, referidas a un mismo conflicto y con la aplicación de idénticas normas. En este sentido, diferentes estudios han detectado numerosos criterios interpretativos que los jueces utilizan o pueden utilizar de modo más o menos indistinto, y que pueden llevar inclusive a soluciones opuestas: decisiones garantistas $\mathrm{y}$ anti-garantistas, decisiones ofensivas frente a los derechos humanos y protectivas hacia éstos o decisiones hostiles y amigables frente al derecho internacional (GARGARELLA, 2008, p. 161).

En este marco, nuestro interés se ha desplazado hacia la búsqueda de explicaciones de esta heterogeneidad de decisiones que van más allá del análisis sobre la interpretación y aplicación normativa $\mathrm{o}$ jurisprudencial en los casos concretos, para analizar por qué se interpretan de tal o cual modo una norma, o se toman ciertos precedentes y se dejan otros de lado, cuáles son los motivos expuestos, las justificaciones, el propósito de tomar uno u otro método de interpretación y lo que comprende uno u otro esquema de razonamiento expresado en las sentencias.

Desde nuestra perspectiva, la explicación de por qué ciertos derechos constitucionales no son garantizados por el poder judicial a ciertas personas, no lo pretendemos hacer considerando a dicho sistema 
como una estructura jerárquica y profesional que aplica mecánicamente la ley, sino como un conglomerado complejo de jueces, abogados, secretarios, que con sus imaginarios, prácticas, capacidades y rutinas, moldean cotidianamente las formas de hacer justicia e interpretar la ley (PALACIO y CONDIOTI, 2007, p. 18).

Para este propósito, proponemos incorporar las nociones de cultura política y cultura jurídica que dan prioridad a las "imágenes" y "representaciones" acerca de lo que es y debería hacer un juez ante la afectación de derechos fundamentales, imágenes que actúan como elementos estructurantes tanto de prácticas sociales como de la praxis institucional de la justicia.

Estas nociones permiten brindar explicaciones más profundas acerca de la construcción de decisiones judiciales que restringen o amplían la protección de los derechos por cuanto en este proceso de creación normativa, no sólo se plasma la decisión de un caso concreto sino que también, se incorporan esquemas de pensamientos y concepciones del mundo, de la vida y de la justicia que determinarán las decisiones en uno u otro sentido.

El objetivo de este trabajo es proponer una nueva línea de explicación de las diferentes posiciones que adoptan los jueces a la hora de garantizar derechos, utilizando las mencionadas categorías. Para este fin, primeramente exponemos los caracteres conceptuales básicos de la cultura política y su estrecha vinculación con la cultura jurídica, y luego realizamos una aplicación de esta propuesta en el caso argentino desde el periodo marcado por la Reforma Constitucional de 1994, de manera de ejemplificar la potencialidad de las categorías aludidas para otorgar nuevas explicaciones acerca del funcionamiento de la estructura judicial y la protección de los derechos constitucionales.

\section{DESARROLLO}

\subsection{El moderno concepto de cultura política}

La noción moderna de "cultura política" surge a partir de la necesidad de búsqueda de nuevas herramientas conceptuales para reemplazar a los modelos teóricos existentes que habían sido insuficientes para explicar ciertos fenómenos políticos. La consideración de la cultura como epifenómeno o reflejo del universo económico 
otorgado por la perspectiva marxista, había provocado una pérdida de centralidad como variable explicativa.

Sin embargo esta tendencia fue progresivamente revertida a partir de la segunda mitad del siglo XX y potenciada desde el periodo de transición hacia regímenes democráticos. La noción de cultura política comienza a ser utilizada como instrumento de análisis para explicar el apoyo que habían tenido por parte de vastos sectores sociales los regímenes autoritarios, la pérdida de centralidad de la política en las sociedades actuales, la influencia de los medios masivos de comunicación en la política, entre muchos otros (LÓPEZ DE LA ROCHE, 2000, p. 95).

La noción de cultura política da cuenta de una zona de contacto entre lo político y lo cultural. Constituye una categoría analítica que intenta explicar ciertos fenómenos políticos teniendo especialmente en cuenta el papel de las creencias y valores en la conformación de un orden político y social (CASALI DE BABOT, 2008). En este sentido, el referente central de la cultura política es el conjunto de relaciones de dominación y de sujeción que son los ejes alrededor de los cuales se estructura la vida política (LÓPEZ DE LA ROCHE, 2000, p. 10).

Se puede ubicar esta categoría en el cruce de la historia cultural y de la historia política e intenta comprender los motivos que conducen al hombre a adoptar tal o cual comportamiento político.

La elaboración teórica y metodológica de este concepto está en permanente construcción y se ha desarrollado tanto dentro del paradigma científico positivista como en el interpretativo.

Dentro del paradigma positivista, el concepto de cultura política ha sido desarrollado en el trabajo pionero de Gabriel Almond y Sidney Verba titulado "The Civic Culture" publicado en 1963. Según dichos autores la cultura política es el patrón de "actitudes individuales y de orientación con respecto a la política para los miembros de un sistema político. Es el aspecto subjetivo que subyace en la acción política y le otorga significados" (ALMOND Y VERBA, 1987). Estas orientaciones individuales incluyen elementos como disposiciones cognitivas, conocimiento o desconocimiento de los objetos políticos, las creencias, orientaciones afectivas, sentimientos de apego, compromisos, rechazos, así como la aplicación de determinados criterios de evaluación a los objetos y acontecimientos políticos.

Siguiendo a Javier de Diego Romero (2006), el trabajo mencionado se inserta en el intento de estudiar la sociedad a partir del 
modelo de las ciencias naturales. La adopción del conductismo por parte de la ciencia política intentará apartarla de las disciplinas humanísticas y convertirá la conducta de los sujetos políticos en su objeto de estudio. De allí el interés por los temas referidos al comportamiento electoral, la participación en la vida partidaria y el análisis de sus valores, motivaciones y actitudes. Desde esta perspectiva, la metodología es de tipo cuantitativa y las herramientas de recolección de datos privilegiadas serán las encuestas y sondeos. Se pretende de esta manera la obtención de un conocimiento generalizable a través de la elaboración de leyes que den cuenta de regularidades cuantificables de la vida política.

Para el paradigma interpretativo, en sentido contrario a la posición anterior, sostiene que la cultura no constituye una variable a la que se puedan imputar causalmente acontecimientos y procesos sociales, modos de conducta o instituciones, sino que es concebida como un contexto de significados dentro del cual puede practicarse la descripción densa de todos esos fenómenos. En este sentido no se trata de esclarecer si determinadas estructuras de significado son el fundamento inmediato del comportamiento y de las estrategias activadas por los sujetos, sino que se busca interpretar los elementos culturales (matrices simbólicas, prácticas rituales, configuraciones discursivas, creencias, valores, etc.) que en última instancia permitan comprender la vida política de la comunidad, explorando el sentido que los actores atribuyen de hecho a su propia actividad (DE DIEGO ROMERO, 2006, p. 249).

De esta forma los estudios han puesto el acento en los imaginarios, mentalidades y representaciones sociales, para identificar cómo se perciben mutuamente diversos grupos de la sociedad. La constitución de la subjetividad en los diferentes ámbitos e instituciones vinculadas a la vida cotidiana son centrales en los trabajos realizados desde este paradigma, por cuanto constituyen modelos de orden, actitudes frente a la autoridad, la relación con el poder, formas de obediencia, etc.

Dentro de este paradigma se enmarcan los presupuestos teóricos y metodológicos provenientes de la renovación de la historia política francesa que le otorgará a la cultura política un profundo enriquecimiento y los caracteres tal como la conocemos actualmente.

Esta última corriente se inserta en la renovación de la historia política llevada a cabo bajo la inspiración de René Rémond para dar una respuesta más satisfactoria en la explicación de los comportamientos políticos. Junto a su principal exponente, también se destacan en el 
desarrollo teórico de esta categoría Serge Berstein, Jean François Sirinelli, Pierre Rosanvallon, Jean Pierre Rioux entre otros, integrados en la universidad de París X-Nanterre, la Fundación Nacional de Ciencias Políticas, el Instituto de Estudios Políticos y el Instituto de Historia del Tiempo Presente (CANAL, 1997, p. 56).

Berstein define la cultura política como un "conjunto coherente cuyos elementos están en relación estrecha unos con otros y que permiten definir una forma de identidad del individuo que se asume como tal." (BERSTEIN, 1999, p. 391).

Este autor expresa que este conjunto es homogéneo pero los componentes son diversos y desembocan en una visión del mundo compartida. Dichos elementos entran en simbiosis con:

una lectura común y normativa del pasado histórico que
connota, positiva o negativamente, los grandes periodos
del pasado, una visión institucional que traduce en el plano
de las organizaciones políticas del Estado los datos
filosóficos o históricos anteriores, una concepción de la
sociedad ideal tal y como la ven los poseedores de esta
cultura y, para expresar el todo, un discurso codificado en
el cual el vocabulario empleado, las palabras clave, las
fórmulas repetitivas contienen significado, mientras que
ritos y símbolos desempeñan en el nivel del gesto y de la
representación visual del mismo papel significante
(BERSTEIN, 1999, p. 391).

Este autor advierte sobre la existencia de diversas culturas políticas y el carácter evolutivo de éstas, que corresponde a un momento dado de la historia cuyo nacimiento es identificable y del que se puede constatar el periodo de elaboración y seguir su evolución en el tiempo. Apunta que el surgimiento de una cultura jurídica no es fortuito sino que constituye la respuesta aportada a una sociedad frente a los grandes problemas y a las grandes crisis de su historia, respuestas lo suficientemente fundadas como para inscribirse en un largo tiempo y trascender las generaciones (BERSTEIN, 1999, p. 396).

Propone asimismo tener en cuenta los vectores por los cuales pasa la integración de esta cultura política como la familia: espacio donde la persona recibe un conjunto de normas, valores y reflexiones que constituyen el primer bagaje político que afianzará o confrontará en las otras instituciones o ámbitos de su existencia como la escuela, el trabajo, el ejército, los partidos políticos, entre otros (BERSTEIN, 1999, p. 397). 
Un autor también central en el desarrollo de este concepto es Jean François Sirinelli, para quien "los valores y creencias de una sociedad [...] están en copropiedad entre la política y la cultura", indicando que la cultura política es el resultado de un proceso complejo:

\begin{abstract}
las grandes ideologías no constituyen más que uno de sus ingredientes, y en ella se amalgaman también, nutriendo y explicitando a la vez estos valores y estas creencias, una memoria específica, compuesta de fechas clave, personajes señeros y, en su caso, de textos canónicos, un vocabulario propio y, a menudo, una sociabilidad particular, ritualizada o no" (SIRINELLI, 1995, p. 30).
\end{abstract}

La riqueza del desarrollo teórico y metodológico de la cultura política se verá potenciada a través del traslado de su objeto de estudio desde "la" política hacia "lo" político. Pierre Rosanvallon (2003, p. 20) expresa que lo político es "una forma de la acción colectiva que se diferencia implícitamente del ejercicio de la política. Referirse a 'lo' político y no a 'la' política es hablar de todo aquello que constituye a la polis."

Según este mismo autor, desde un aspecto metodológico, la cultura política busca reconstruir la manera como los individuos y los grupos han elaborado su comprensión de las situaciones, de enfrentar los rechazos y las adhesiones a partir de los cuales han formulado sus objetivos, de volver a trazar de algún modo la manera como su visión del mundo ha acotado y organizado el campo de sus acciones (ROSANVALLON, 2003, p. 26).

Este concepto permite visualizar, más que la realidad en sí, la manera en que los individuos y las sociedades se la representan (CASALI DE BABOT, 2008, p. 77). Le interesa indagar más por los sentidos que por la genética u origen de determinadas acciones políticas. De esta manera, la cultura política, como resalta Berstein, en su condición de "guía de lectura de lo político", intenta dar una explicación de los comportamientos políticos por una fracción del patrimonio cultural adquirido por un individuo durante su existencia y comprender los motivos que conducen al hombre a adoptar tal o cual comportamiento político (BERSTEIN, 1999, p. 400). 


\title{
1.2 La cultura política y su vinculación con la cultura jurídica
}

Consideramos que dentro del marco conceptual de la cultura política el derecho es un elemento central a tener en cuenta. El modelo de dominación de los estados contemporáneos asienta su legitimidad en el denominado "poder legal-racional" desarrollado por Max Weber (1964) basado en la creencia en la legalidad de las normas del régimen, estatuidas de modo racional a través de la ley abstracta e impersonal.

El derecho, en cuanto forma por excelencia del poder simbólico de nominación que crea las cosas nombradas (BOURDIEU Y TEUBNER, 2000, p. 198), antes de regular la sociedad la imagina, crea modelos mentales del hombre y de las cosas, de los vínculos sociales y de las relaciones políticas y jurídicas (HESPANHA, 2000, p. 58). La internalización de estas "imágenes" y la influencia que tienen sobre las tomas de posición y decisiones acerca de lo jurídico, hace particularmente útil incorporar las bases teóricas de la cultura política a la cultura jurídica.

La cultura jurídica de modo general ha sido definida como:

\begin{abstract}
un conjunto de actitudes fuertemente vinculadas e históricamente condicionadas acerca de la naturaleza del Derecho, su rol social y político, la organización y operatividad del sistema legal, el modo en el que el Derecho es o debería ser elaborado, aplicado, estudiado, perfeccionado y enseñado (SUÁREZ LLANO, 2004, p. 21).
\end{abstract}

Desde un punto de vista más específico y cercano a la cultura jurídica evidenciada en los órganos jurisdiccionales ha sido definida como el "conjunto de las interpretaciones, suministradas sobre todo por los operadores jurídicos, relacionados con la aplicación considerada correcta de textos normativos" (GUASTINI y REBUFFA, 1995, p. 25) y también como el "conjunto de los modelos de razonamiento utilizados por los juristas, tanto en función doctrinal como jurisprudencial" (GUASTINI y REBUFFA, 1995, p. 25). De esta forma el análisis de la cultura jurídica significa para estos autores dos cosas: 1) el estudio de lenguajes técnicos y de las operaciones prácticas que se llevan a cabo con esos lenguajes, y 2) el estudio de las modalidades organizativas de los operadores del derecho. 
En este sentido, desde los ámbitos académicos pertenecientes a una visión crítica del derecho se ha empezado a tener en cuenta el papel ejercido por la ciencia jurídica, a través de la elaboración de las "imágenes" y de los "paradigmas" de Estado y de Derecho, sobre la formación de las clases dirigentes, proyección, consolidación ideológica y funcionamiento práctico de las instituciones (FERRAJOLI, 2010, p. 16).

De esta manera del mismo modo en que la cultura política, como categoría analítica se ocupa de analizar los valores y creencias en torno a la política, su simbología, imaginario, etc., por su parte la cultura jurídica vendría a constituir una herramienta de análisis encargada de analizar dichos elementos pero sobre lo jurídico.

No se puede estudiar una cultura en sí sino en sus discursos y prácticas (CASALI DE BABOT, 2008, p. 73). En este sentido los valores y creencias acerca de lo jurídico pueden ser rastreados a través de sus diversas manifestaciones discursivas como la legislación, la doctrina o la jurisprudencia, y también en la práctica concreta de sus operadores.

Entre estos elementos de análisis cobra relevancia el estudio de las sentencias, como discurso donde se plasma con mayor magnitud ese conjunto de valores e imágenes sobre el derecho, por cuanto los jueces constituyen los sujetos socialmente legitimados para decir en última instancia qué es el derecho.

En esta dirección, al igual que la cultura política, es posible identificar diversas culturas jurídicas dentro de un sistema normativo vinculadas a aquellas imágenes, creencias o concepciones, operativizadas por los jueces, acerca de lo que es o debe ser el poder judicial o las actuaciones de los órganos jurisdiccionales. De esta forma, en todo orden jurídico, a través del análisis de las sentencias, es posible identificar diversas culturas jurídicas que tendrán como consecuencia una diferente toma de posición respecto de la garantía de los derechos, que a modo de ejemplo, realizamos un breve análisis en el caso argentino.

\subsection{El estudio las diferentes culturas jurídicas en el caso argentino}

En Argentina, desde la recuperación de la democracia en 1983, se ha podido observar el surgimiento de una nueva cultura jurídica constitucional dado por el reconocimiento del valor vinculante de la Constitución como norma superior y eje organizador del sistema jurídico y político. Este proceso tuvo como consecuencia directa un mayor 
protagonismo del Poder Judicial en el funcionamiento del sistema democrático, último garante de la protección de los derechos.

Como resalta Garriga (2010) este valor y jerarquía dado al texto constitucional da cuenta, antes que nada, de un cambio profundo del orden jurídico que ha transitado desde un orden jurídico legal, que identifica el derecho con la ley, hacia un orden jurídico constitucional, que identifica el derecho a partir de los derechos constitucionalmente reconocidos. De esta forma expresa dicho autor que:

aunque el cambio de orden jurídico comporte o pueda comportar el cambio de normas y de formulaciones normativas, es en último término una cuestión de cultura de cultura institucionalizada- porque depende decisivamente de lo que a partir de unas $u$ otras formulaciones reconozcan como derecho los participantes (GARRIGA, 2010, p. 62).

Este proceso de cambio se afianza y normativiza con la Reforma Constitucional de 1994 que modifica de manera sustancial el sistema jerárquico de fuentes del derecho, dando lugar a la supremacía del llamado Bloque de Constitucionalidad Federal integrado por la Constitución y los Tratados Internacionales de Derechos Humanos con rango constitucional.

Esta constitucionalización del sistema ha ocasionado un cambio importante en las prácticas jurisprudenciales de los tribunales. En este sentido, el juez para la materialización de los derechos constitucionales se ha visto obligado a ejercer su función jurisdiccional con parámetros interpretativos nuevos y formas de razonamiento judicial más complejos (CARBONELL, 2007, p.10). La resignificación y recreación de sus prácticas ha sido entendido como el tránsito desde un juez-funcionario, encargado de determinar la regla y aplicarla conforme a un criterio lógico sin ninguna intervención, hacia un juez-político, en la medida que define a través de sus decisiones contenidos antes reservados a los poderes legislativo y ejecutivo (ZAGREBELSKY, 2009; ABRAMOVICH, 2006).

Este proceso de cambio de orden jurídico al que hacemos referencia, ha puesto en evidencia dentro de la jurisprudencia contemporánea, la convivencia de al menos dos culturas jurídicas diferentes y antagónicas: la cultura jurídica legalista y la cultura jurídica constitucional, cada una sosteniendo una imagen del Estado y del 
Derecho que tendrán como consecuencia la aplicación de un diferente estándar de protección.

La cultura jurídica legalista, como lo expresa Luigi Ferrajoli (2010), se basa en la idea del Estado como entidad natural y necesaria, de voluntad omnipotente, ignorando tanto la soberanía popular como el valor constitucional en cuanto sistema de límites y garantías.

Desde esta óptica, la principal fuente de derecho es la ley, sin fundamento constitucional, sino sustentada en el paradigma civilista asentado en la tradición. Este paradigma proporcionará los postulados de neutralidad y apoliticidad del derecho, la plenitud y coherencia del ordenamiento, el carácter técnico avalorativo de las interpretaciones, tanto doctrinales como judiciales, postulándose de esta manera la doctrina jurídica como "ciencia" y la actividad del juez como "técnica".

La cultura jurídica constitucional, desde otra perspectiva, concibe al Estado como instrumento artificial, cuya finalidad es la tutela de las personas que lo han construido. Postula la supremacía constitucional como fuente de fuentes, que con carácter vinculante, establece sus contenidos sustanciales a todo el ordenamiento inferior y a todas las relaciones horizontales y verticales.

La adopción entre una y otra perspectiva, como ya lo expresamos, tiene diferentes consecuencias en el funcionamiento concreto del campo jurídico. Desde la cultura jurídica legalista, los derechos fundamentales no son límites externos y condiciones de legitimidad política del artificio estatal, como lo concibe la cultura jurídica constitucionalista, sino autolimitaciones de la soberanía del Estado y, por ello, son concesiones disponibles.

De esta manera, consideramos que las creencias, visiones, valoraciones, imaginarios, intereses, entre otros, son determinantes en el funcionamiento del sistema judicial y en la protección concreta de los derechos. En este aspecto, un estudio reciente (CARO ZOTTOLA, 2013) realizado sobre determinadas prácticas jurisdiccionales en Argentina, detectó la divergencia de criterios de los jueces en la construcción de las sentencias vinculadas a la adhesión a una u otra cultura jurídica, manifestada en tres puntos principales: la aplicación de las fuentes del derecho, la construcción de los hechos y los modos de generación de información necesarios para la resolución de un conflicto.

Respecto de la aplicación de las fuentes del derecho, la cultura jurídica legalista impone esquemas decisorios que dan prioridad a la aplicación de fuentes normativas infraconstitucionales, como pueden ser 
el Código Civil, los códigos de minería o los de procedimientos, contra normas de raigambre constitucional. Esto se evidencia en las disputas donde las partes afectadas por una sentencia de este tipo, articulan las acciones de inconstitucionalidad con el objetivo de reestablecer la supremacía de la Carta Magna.

Por otra parte, la cultura legalista propone también la prioridad de aplicación de las normas procesales o rituales frente a las normas sustantivas que establecen el contenido de los derechos. En este sentido, la negación de acciones de amparo o de inconstitucionalidad, basadas en la falta de los requisitos de forma, son elocuentes de esta postura. También son ejemplos de esta orientación los rechazos que se fundamentan en la existencia de otras vías más idóneas que el amparo para la defensa de los derechos o en la consideración de las normas constitucionales como programáticas y no operativas que necesitan de una precisión normativa para su aplicación.

En sentido contrario, las decisiones enmarcadas dentro de la cultura jurídica constitucional priorizan la aplicación de la acción de amparo como garantía específica para la defensa de los derechos constitucionales, y sobreponen el contenido de los derechos frente al ritualismo o formalismo procesal.

En cuanto al segundo punto, relacionado con la construcción de los hechos, observamos que existe una divergencia entre dos formas de razonamiento jurídico y selección de los acontecimientos considerados relevantes en un conflicto.

La cultura legalista se manifiesta en modelos de razonamiento que priorizan el análisis abstracto de los hechos en relación con las normas, sin la consideración del contexto que rodea a las disputas. Frente a este modelo, la cultura jurídica constitucional basa las decisiones judiciales en la consideración del contexto y la calidad de sujetos situados conformados en un espacio y tiempo determinado.

Estas consideraciones anteriores se vinculan con un tema central, constituido por las diferentes posiciones que puede adoptar el juez en su actuación dentro del proceso. La cultura jurídica constitucionalista postulará la necesidad de una judicatura activa que tome decisiones encaminadas a la protección de las partes más débiles del proceso, para evitar que la defensa de sus derechos se convierta en ilusoria. En este sentido, las medidas compensatorias de los desequilibrios de las partes cobran gran importancia, por cuanto, conforme a los estándares internacionales de derechos humanos, la igualdad ante la ley no es 
posible si no se solucionan las desventajas estructurales de las partes en el mismo proceso (CORTE INTERAMERICANA DE DERECHOS HUMANOS, 1999, párr. 117).

Entre estas medidas de compensación, guardan gran trascendencia las llamadas "medidas para mejor proveer", impulsadas de oficio por el propio juez, mediante las cuales incorpora mayor información y conocimiento del conflicto a través del asesoramiento de especialistas, universidades u otras instituciones prestigiosas. Estas medidas tienen, por un lado, el objetivo de lograr mayor conocimiento y poder brindar una sentencia más justa, y por el otro, también buscan suplir deficiencias probatorias de la parte más débil vinculadas no a su negligencia, sino a sus dificultades estructurales que pueden provocar incluso, ante la ausencia de pruebas, la pérdida de sus derechos.

Desde una posición contraria, relacionada con la cultura jurídica legalista, las medidas de compensación rompen la igualdad entre las partes alterando la garantía del debido proceso, y prefieren dejar libradas a éstas la defensa de sus derechos de acuerdo con las capacidades particulares de cada una.

Un punto claro que explica la divergencia entre posturas $\mathrm{y}$ sentencias, lo constituye el grado de complejidad que se otorga a los casos judiciales, lo que derivará en una diferente actitud respecto de la generación de conocimiento para su solución.

Para la cultura jurídica que tiene como centro la ley, el conflicto se reduce al microespacio de las disputas vinculadas a los supuestos de hecho enunciados en las normas. De esta forma, la producción de conocimiento es limitada y se prescinde de medios probatorios complejos.

Desde la cultura jurídica constitucional, por el contrario, los casos son percibidos como altamente complejos que requieren de un esfuerzo interpretativo mayor y por lo tanto, de una amplia generación de conocimiento para lograr una decisión justa.

Desde esta última perspectiva, en ciertos procesos judiciales pueden observase medidas tendientes a producir de modo interdisciplinario diferentes conocimientos relevantes del caso. Si ponemos como ejemplo la afectación de derechos constitucionales en casos que tocan temas culturales, las pericias antropológicas o las investigaciones en ciencias sociales son sumamente utilizadas desde esta postura. 
De esta manera podemos ver en un mismo sistema jurídico y regido por el mismo sistema de reglas, una amplia heterogeneidad de decisiones, incluso antagónicas, referidas a un mismo conflicto, fuertemente vinculadas a las culturas jurídicas a las que hicimos referencia. Se evidencia de esta forma que los diferentes pronunciamientos constituyen una de las diversas y variadas opciones posibles para la resolución del caso, lo que pone de manifiesto la dimensión política de las decisiones judiciales.

Siguiendo a Rosanvallon (2003), esta dimensión política a la que aludimos, no se refiere al ejercicio de la política como competencia partidaria por el ejercicio del poder, o a la acción gubernamental, sino que se hace referencia a la vinculación de las sentencias con "lo político", entendido como "una modalidad de existencia de la vida comunitaria". Parafraseando a este autor, queremos enunciar que las decisiones judiciales que fijan el conflicto en uno u otro sentido, en cierta medida "hablan" de lo político, es decir, hablan del poder y de la ley, del Estado y de la nación, de la igualdad y de la justicia, de la identidad y de la diferencia, de la ciudadanía y de la civilidad.

Así, la pugna interna del campo jurídico manifestada en las diversas sentencias insertas en diferentes culturas jurídicas, se basa en la lucha por imponer diferentes contenidos a esta modalidad de existencia de la vida comunitaria, en donde las imágenes y representaciones jugarán un papel fundamental en su definición.

\section{CONSIDERACIONES FINALES}

Como vimos en este trabajo, el peso de las creencias, visiones, valoraciones, imaginarios, intereses, por parte de los operadores del derecho, tienen gran relevancia en el funcionamiento del sistema judicial y en la protección concreta de los derechos. Esto lo notamos en las diferentes formas de resolución de los conflictos, vinculado a las posiciones sobre la función judicial y la actuación del juez.

En el caso argentino, el reconocimiento de los derechos humanos en la Constitución de 1994 que mencionamos, no ha derivado de una aplicación directa de éstos, debido a que entre la norma y su aplicación por los jueces, existen un conjunto de interpretaciones, valores, creencias, imágenes, intereses, que modelan diferentes formas de razonamiento y creación del derecho que constituye lo que denominamos "cultura jurídica". 
De esta forma, las dificultades en la garantía de los derechos constitucionales por parte de los órganos jurisdiccionales evidenciadas en las sentencias, surgen como consecuencia de la modificación del orden jurídico que desplazó a la ley como eje central, para ubicar a la Constitución como fuente normativa superior del sistema. Así, los tratados de derechos humanos han incorporado, sobre una estructura anterior, una nueva concepción del orden social y del Estado, nutriendo al ordenamiento jurídico y político de nuevos valores que tienen en común la promoción de la igualdad entre los integrantes del cuerpo social.

En nuestro trabajo pudimos identificar al menos dos culturas jurídicas diferentes y antagónicas en los órganos judiciales: la cultura jurídica legalista y la cultura jurídica constitucional, cada una sosteniendo una diferente concepción del Estado y del derecho.

De allí la utilidad de las nociones de cultura política y jurídica que proponemos. El desarrollo teórico de la cultura política puede constituir una fundamentación inicial para el desarrollo de la cultura jurídica. Como categoría de análisis es útil para explicar los fenómenos jurídicos teniendo en cuenta otros elementos diferentes a lo estrictamente institucionales, otorgando poder explicativo a las imágenes, los valores, los ritos y mitos que tienen concreta consecuencia en la protección o no de los derechos constitucionales.

En este sentido, la explicación de problemas relacionados con la institución judicial como la falta de efectivización de los derechos o el acceso a la justicia puede ser analizada a través de la reconstrucción de los casos judiciales paradigmáticos. En este marco los expedientes judiciales y el conjunto de documentos que lo componen resulta pieza clave para dicho trabajo.

En efecto, el expediente judicial es iniciado generalmente por una demanda de un sujeto damnificado a la que continúa su contestación y finaliza en la sentencia. En estos documentos se puede observar las posturas frentes al problema y la visión institucional del mismo, permitiendo analizar no sólo lo que explícitamente aparece, sino además, esquemas de pensamiento subyacentes, concepciones del mundo, de la vida y de la propia función judicial.

Intentar la explicación de fenómenos sociales, particularmente políticos y jurídicos a través de estudio de los aspectos culturales, supone estudiar zonas grises, porosas, no definidas totalmente que potencian, enriquecen y complementan los estudios destinados al análisis puramente 
institucional de la justicia; lo que permite una comprensión más profunda y compleja de la dinámica judicial y un fructífero diálogo interdisciplinario entre la política y el derecho.

\section{BIBLIOGRAFÍA}

ABRAMOVICH, V. (2006). Acceso a la justicia y nuevas formas de participación en la esfera política. En H. Birgin y B. Kohen, Acceso a la justicia como garantía de igualdad. Instituciones, actores y experiencias comparadas. (1a. ed., 59-82) Buenos Aires: Biblos.

ALMOND, Gabriel y VERBA, Sidney. The Civic Culture. Political Attitudes and Democracy in Five Nations. Newbury Park: Sage Publications, 1989.

BERSTEIN, Serge. La cultura política. En RIOUX, Jean Pierre y SIRINELLI, Jean Francois (dir.). Para una historia cultural. México: Taurus, 1999.

BOURDIEU, Pierre y TEUBNER, Gunther. La fuerza del derecho. Bogotá: Siglo del Hombre Editores, 2000.

CANAL, Jordi. Maurice Agulhon: historia y compromiso republicano. Revista Historia Social n. 29, p. 47-72. 1997.

CARO ZOTTOLA, Luis Esteban. El acceso a la justicia en núcleos duros de pobreza del Norte Grande Argentino (2001-2007). Tesis (Doctorado en Humanidades. Área Derecho). Facultad de Filosofía y Letras. Universidad Nacional de Tucumán, 2013.

CASALI DE BABOT, Judith. Breve vocabulario de cultura política. Aportes para una cultura democrática. Tucumán: Universidad Nacional de Tucumán, 2008.

CORTE INTERAMERICANA DE DERECHOS HUMANOS (Corte I.D.H.), "El Derecho a la Información sobre la Asistencia Consular en el Marco de las Garantías del Debido Proceso Legal”. Opinión Consultiva OC-16/99 de 1 de octubre de 1999. Serie A No. 16. 
DE DIEGO ROMERO, Javier. El concepto de 'cultura política' en ciencia política y sus implicaciones para la historia”. Revista Ayer, n. 61, p. 233-266. 2006.

FERRAJOLI, Luigi. Cultura jurídica y paradigma constitucional. La experiencia italiana del siglo XX. Lima: Palestra, 2010.

GARGARELLA, Roberto. Un papel renovado para la Corte Suprema. Democracia e interpretación judicial de la Constitución. En: GARGARELLA, Roberto (coord.), Teoría y Crítica del Derecho Constitucional, Tomo I, Democracia. Buenos Aires: Abeledo Perrot, 2008.

GARRIGA, Carlos. Continuidad y cambio del orden jurídico. En: GARRIGA, Carlos (Coord.), Historia y Constitución. Trayectos del constitucionalismo hispano. México: CIDE: Instituto Mora: El Colegio de Michoacán: ELD: HICOES: El Colegio de México, 2010.

GUASTINI, Riccardo y REBUFFA, Giorgio. Introducción. En TARELLO, Giovanni, Cultura jurídica y política del derecho. México: Fondo de Cultura Económica, 1995.

HESPANHA, Antonio Manuel. Cultura jurídica europea. Síntesis de un milenio. Lisboa: Tecnos, 2000.

LÓPEZ DE LA ROCHE, Fabio. Aproximaciones al concepto de cultura política. Revista Convergencia n. 7, p. 93-123, 2000.

MAX WEBER. Economía y Sociedad. México: Fondo de Cultura Económica, 1964.

PALACIO, Juan Manuel y CANDIOTI, Magdalena. Justicia, política y derechos en América Latina. Apuntes para un diálogo interdisciplinario. En PALACIO, J. M. y CANDIOTI M. (comp.). Justicia, política y derechos en América Latina, Buenos Aires, Prometeo, 2007.

ROSANVALLON, Pierre. Por una historia conceptual de lo político. Lección inaugural en el Collége de France. México: Fondo de Cultura Económica, 2003. 
SIRINELLI, Jean-François. El retorno de lo político". Revista Historia Contemporánea, n. 9, p. 25-35. 1995.

SUÁREZ LLANOS, María Leonor. La 'Cultura Jurídica' y el 'Pluralismo Jurídico'. Problemas de definición.”. UNED Boletín de la Facultad de Derecho n. 24, p. 15-60. 2004.

ZAGREBELSKY, Gustavo. El derecho dúctil. Ley, derechos, justicia. Madrid: Trotta, 2009. 